\title{
"¿QUÉ INDIAS HAY DONDE NO HAY COCHE?": EL CARRUAJE COMO OBJETO DE ANÁLISIS HISTÓRICO Y ARTÍSTICO EN ESPAÑA Y EN LA AMÉRICA VIRREINAL
}

\author{
“QUÉ INDIAS HAY DONDE NO HAY COCHE?”: \\ CARRIAGES AS WORK OF HISTORICAL AND ARTISTIC \\ ANALYSIS IN SPAIN AND VICEREGAL AMERICA
}

\author{
Álvaro Recio Mir \\ Universidad de Sevilla. España \\ alvarorecio@us.es
}

\begin{abstract}
Aproximación metodológica al análisis histórico y artístico de los carruajes en España y en la América virreinal. Se emplean para ello tres tipos de fuentes fundamentales: legales, documentales e iconográficas. Ello permite ver la relación del coche con el urbanismo, la arquitectura, la escultura, el retablo, la pintura y las artes suntuarias.

Palabras clave: coche; España; América; Historia; Arte.
\end{abstract}

This paper is a methodological approach to a historical and artistic analysis of the carriages in Spain and Viceregal America. There are used for it three types of fundamental sources: legal, documentary and iconographic. It allows seeing the relation of the carriages with urbanism, architecture, sculpture, altarpieces, painting and decorative arts.

Keywords: carriage; Spain; America; History; Art.

\section{UN APUNTE HISTORIOGRÁFICO}

Aunque Domínguez Ortiz ya señaló que el coche es un asunto que interesa tanto al urbanismo como al arte, la economía o las mentalidades, solo en fechas muy recientes la historiografía española se ha ocupado de él como objeto digno de análisis histórico. Dos monografías se han convertido en verdaderos pilares de futuros estudios al respecto; la primera es Historia del carruaje en España, 
coordinada por Eduardo Galán Domingo, y Poder, lujo y conflicto en la Corte de los Austrias. Coches, carrozas y sillas de mano, 1550-1700, de la que es autor Alejandro López Álvarez ${ }^{1}$. España se ha sumado así a otras naciones europeas que desde hace tiempo entienden que los vehículos representativos fueron, más que meras anécdotas, piezas fundamentales en el discurso histórico, ya que desde su difusión en el siglo XVI se convirtieron en ostentosos símbolos de estatus de las clases privilegiadas durante todo el Antiguo Régimen y aun hasta su casi definitivo periclitar tras de la I Guerra Mundial.

Aunque es una cuestión aún por estudiar, cabe intuir que el protagonismo de España en el mundo del coche -en principio solo secundario, sobre todo si se compara con el jugado por Francia e Inglaterra- radica en su inmensa proyección americana. Sin duda, la llegada de carruajes a los más remotos confines de sus virreinatos dio carácter universal a este invento europeo. A ello se suma el desarrollo que tales vehículos alcanzaron en las principales ciudades americanas, particularmente en las grandes capitales virreinales. De esta forma, la carrocería hispánica alcanzaría durante la Edad Moderna una preeminencia indiscutible, únicamente comparable con la que solo en el siglo XIX logró la inglesa.

Todo parece indicar que los coches abundaron desde un primer momento en la América virreinal, como prueba la pregunta planteada en la comedia Guárdate del agua mansa de Calderón de la Barca: “qué Indias hay donde no hay coche?”2. Pese a ello, hasta ahora ha sido una cuestión apenas estudiada por la historiografía americanista. En este sentido, el único estudio que ha abordado la cuestión de forma genérica en todo el ámbito virreinal es el de Ramón Serrera, Tráfico terrestre y red vial en las Indias españolas ${ }^{3}$. De las dos cortes virreinales a fines del siglo XVI y durante el XVII, se ocupa un artículo de López Álvarez, mientras que de Lima en el XVII sobresale otro documentadísimo de Guillermo Lohmann Villena ${ }^{4}$. México cuenta con el capítulo que le dedicó al asunto Manuel Romero de

${ }^{1}$ Véanse respectivamente DOMÍNGUEZ ORTIZ, Antonio: "Los primeros coches de caballos en España", Historia 16, 95, 1984, pp. 35-40; GALÁN DOMINGO, Eduardo (coord.): Historia del carruaje en España. Madrid, 2005; y LÓPEZ ÁLVAREZ, Alejandro: Poder, lujo y conflicto en la Corte de los Austrias. Coches, carrozas y sillas de mano, 15501700. Madrid, 2007.

${ }^{2}$ La cita la tomamos de LÓPEZ ÁLVAREZ, Alejandro: "Los vehículos representativos en la configuración de la corte virreinal: México y Lima, 1590-1700", en GARCÍA DE SANTO-TOMÁS, Enrique (coord.): Materia crítica. Formas de ocio y de consumo en la cultura áurea. Vervuert, 2009, pp. 269-291.

${ }^{3}$ SERRERA, Ramón Ma: Tráfico terrestre y red vial en las Indias españolas. Madrid, 1993.

${ }^{4}$ LÓPEZ ÁLVAREZ, Alejandro: "Los vehículos representativos...”, op. cit.; y LOHMANN VILLENA, Guillermo: "De coches, carrozas y calesas en Lima en el siglo XVII: una aproximación”, Revista del Archivo General de la Nación, 14, 1996, pp. 111-157. A ello hay que sumar RECIO MIR, Álvaro: "La carrocería peruana virreinal a partir de un 
Terreros en su monografía sobre las artes industriales novohispanas; los breves pero valiosos libros de Francisco J. Hernández y de Marita Martínez del Río, y los artículos que sobre el gremio de carroceros de México han aparecido recientemente ${ }^{5}$.

Sin duda, se trata de un importante punto de partida. No obstante, debe darse un paso más, ya que el coche no solo es un objeto digno de análisis histórico, también es una obra de arte de primer orden, en cuya materialización confluyeron diversas especialidades creativas, ya que a las carroceras se sumaron la escultura, pintura, platería o la tapicería ${ }^{6}$.

\section{ALGUNAS CUESTIONES CONCEPTUALES}

La primera distinción fundamental hay que hacerla entre carros y coches. Los primeros, cuyos orígenes se encuentran en la Antigüedad, son vehículos de tracción animal que se diferencian de los coches en que estos sumaron a una similar estructura un sistema de suspensión para una mayor comodidad. El coche -término al parecer de origen húngaro- solo surgió al final de la Edad Media y se difundió por Europa en el siglo XVI, adquiriendo de inmediato carácter representativo, hasta el punto de ser empleado por las cortes del continente de forma sistemática. Ello alteró la forma de exponer el monarca a sus súbditos y supuso una reestructuración de la casa del rey, en concreto de las caballerizas?.

La variedad de los coches es difícil de reducir a sistema, ya que fue enorme la multiplicidad de tipologías que llegaron a desarrollarse. Pero a estos vehículos hay que sumar aún otras formas de transporte que carecían de ruedas, como

memorial del gremio de Lima de 1778", Laboratorio de arte, 25, 2013, pp. 515-531. Sobre Argentina véase TORRE REVELLO, José: "Los coches en el Buenos Aires antiguo", Historia, 3, 1956, pp. 161-163.

${ }^{5}$ ROMERO DE TERREROS, Manuel: Las artes industriales en la Nueva España. México, 1923, pp. 77-85; HERNÁNDEZ, Francisco Javier: Carruajes, sillas, jaeces. México, 1948; MARTÍNEZ DEL RÍO DE REDO, Marita: El transporte en la historia de México. México, 1960; RECIO MIR, Álvaro: "Un nuevo arte en movimiento para la ostentación social: los primeros coches novohispanos y las ordenanzas del gremio de carroceros de la ciudad de México de 1706", Anales de Instituto de Investigaciones Estéticas, 101, 2012, pp. 13-38; RECIO MIR, Álvaro: "Evolución de la carrocería novohispana: segundas ordenanzas del gremio de la ciudad de México", Historias, 81, 2012, pp. 17-34; y RECIO MIR, Álvaro: "La carrocería novohispana al final del virreinato: el pleito múltiple del gremio de la ciudad de México de 1799", Atrio, 21, 2015, pp. 108-121.

${ }^{6}$ Véase RECIO MIR, Álvaro: "La construcción de coches en la Sevilla barroca: confluencias artísticas y rivalidades profesionales", en Actas del congreso internacional Andalucía barroca. T. I. Sevilla, 2009, pp. 405-416.

${ }^{7}$ Esencial sobre todo ello es LÓPEZ ÁLVAREZ, Alejandro: Poder, lujo y conflicto..., op. cit. 
las literas, las sillas de manos y los trineos, que también se hicieron frecuentísimos. Como objeto de estudio histórico y artístico interesan tanto los coches y demás vehículos citados, como los carros, ya que aunque una vez surgidos aquellos, estos quedaron reducidos al transporte de mercancías, no se puede olvidar la enorme importancia que tuvieron los carros triunfales en las fiestas barrocas. Tales carros triunfales fueron ejecutados por los mismos artífices que los coches. Así, las ordenanzas sevillanas del gremio de maestros de hacer coches de 1703 señalan que para alcanzar la maestría estos profesionales debían saber ejecutar distintos tipos de coches, además de carros triunfales ${ }^{8}$.

Lógicamente, el coche en sí no tiene sentido como elemento aislado, ya que solo alcanza su poliédrica significación en movimiento, por lo que al propio vehículo y a sus ocupantes hay que unir otros elementos que son esenciales: los animales de tiro, fundamentalmente caballos y mulas; el arnés o conjunto de correas y hebillas que une tiro y coche, y el personal de servicio, básicamente cocheros y lacayos. La suma de todos estos elementos - coche, tiro, arnés, ocupantes y personal- se denomina enganche (Figura 1$)^{9}$.

Además, en tales conjuntos no se limita lo artístico al vehículo, ya que los arneses alcanzaron un valor suntuario innegable, igual que los lacayos, que emplearon vistosísimos uniformes - de camino, de diario y de gala-. Por ello y por alcanzar su auténtica dimensión en movimiento, los coches hay que entenderlos como cinéticas obras de arte tota $1^{10}$.

\section{FUENTES LEGALES: USO Y LUJO}

El estudio del coche debe partir de una premisa evidente: la pérdida de la inmensa mayoría de los ejemplares que existieron. De los siglos XVI y XVII apenas se conservan un puñado. Algo más numerosos son los del XVIII, pero sin duda son del XIX y, sobre todo, del XX la inmensa mayoría de los conservados. En el caso español y americano tal realidad se hace, si cabe, aún más dramática, ya que resultan excepcionales incluso los del siglo XVIII. Por ello, estudiar esta cuestión en el marco del mundo hispánico requiere hacerlo a través, más que de los propios coches, de diversas fuentes que cabe agrupar en cuatro ámbitos fundamentales: literarias, legales, documentales e iconográficas.

${ }^{8}$ RECIO MIR, Álvaro: "La construcción de coches...”, op. cit., p. 408.

9 RIVERO MERRY, Luis: Manuel de enganches. Sevilla, 1986.

${ }_{10}$ Aunque no lo vayamos a desarrollar, hay que insistir en la enorme suntuosidad que en el ámbito americano alcanzaron los arneses. Significativas son las palabras de Balbuena en su Grandeza mexicana: "Ricos jaeces de libreas costosas/ de aljófar, perlas, oro y pedrería, /son en sus plazas ordinarias cosas". DE BALBUENA, Bernardo: Grandeza mexicana, fragmentos de Siglo de oro y El Bernardo. México, 2008, p. 22. 
Las fuentes literarias han sido las más analizadas hasta ahora, por ello aquí apenas las mencionaremos. El fenómeno del "encochado" se convirtió en un tópico de la literatura española y americana del Siglo de Oro. Esta patológica obsesión por los coches, comparable con la actual por el automóvil, se evidenció sobre todo en las comedias ${ }^{11}$.

Esencial en el caso americano son las referencias de cronistas y viajeros, como por ejemplo Thomas Gage, que indicaba que los coches que ruaban por México eran "más caros que los de la Corte de Madrid y de cualquier otra parte de la Cristiandad; porque allí no faltaban ni plata, ni oro, ni piedras preciosas, ni paños dorados, ni tampoco las mejores sedas traídas de la China para enriquecer estos carruajes"12.

No obstante, queremos insistir en esta ocasión en las fuentes legales, en las que destacan dos ámbitos de reglamentación: el relativo al uso de los carruajes y el que se ocupó en controlar su lujo excesivo. La primera cuestión ha sido exhaustivamente analizada por López Álvarez, que ha probado que la monarquía católica, a partir de una legislación vacilante y aun contradictoria, controló el acceso al coche de solo una parte de la sociedad y, a la vez, se ganó a la misma reconociéndole tal derecho. El coche se convirtió así en elemento distintivo del ámbito cortesano y manifestación del lugar que cada persona ocupaba en esa sociedad cortesana, de la cual no se podía formar parte sin coche ${ }^{13}$.

En el ámbito legal sobre el uso del coche es del máximo interés la real cédula de Felipe II de 24 de noviembre de 1577 en relación a América, en la que declaró: "por cuanto somos informado que [...] se han comenzado a usar y usan andar en coches y carrozas muchas gentes y que eso va cada día creciendo, de manera que no se tiene tanta cuenta con el ejercicio de los caballos [...] mandamos y expresamente prohibimos y defendemos agora, ni de aquí adelante, ni algunas personas de cualesquiera estado o condición que sean no puedan andar ni anden en coches ni carrozas, no los tengan ni usen de ellos en manera alguna en la dicha Nueva España ni en otra parte alguna de las dichas nuestras Indias, Islas y Tierra Firme del mar Océano [...] y que, además, ninguna persona pueda pasar coche ni carroza alguna a las dichas nuestras Indias, ni las hacer, ni labrar en ellas"14.

De este texto nos gustaría ahora al menos apuntar dos cuestiones apenas tratadas. En primer lugar, el comercio de coches entre España y América, del que

${ }^{11}$ Las fuentes literarias españolas son analizadas en LÓPEZ ÁLVAREZ, Alejandro: Poder, lujo y conflicto..., op. cit.; y las americanas en LÓPEZ ÁLVAREZ, Alejandro: "Los vehículos representativos...", op. cit.

12 GAGE, Thomas: Viajes por la Nueva España y Guatemala. Madrid, 1987, p. 165.

${ }^{13}$ LÓPEZ ÁLVAREZ, Alejandro: Poder, lujo y conflicto..., op. cit., pp. 319-ss.

${ }^{14}$ SERRERA, Ramón Ma': Tráfico terrestre..., op. cit., pp. 293-294. 
casi nada sabemos, aunque la norma citada prueba su existencia ${ }^{15}$. En segundo lugar, la temprana construcción de coches en América. Ello enlaza con una cuestión sí estudiada algo en España, la de los gremios de maestros de hacer coches, de los que se tienen estudios de Madrid y Sevilla ${ }^{16}$. La consecución de tales gremios no estuvo exenta de polémica, ya que el carácter interdisciplinar que requería la construcción de un carruaje se adaptaba mal al encorsetado sistema gremial de origen medieval. Si bien es cierto que las cajas, trenes y ruedas de estos vehículos estuvieron en principio vinculados a la carpintería, sus arneses eran propios del gremio de correeros, que litigaron en el caso sevillano para no perder tan importante actividad profesional. A eso se sumaron pronto otros litigios en relación a su decoración, ya que pintores y escultores, que en el barroco alcanzaron un papel esencial en los vehículos, supusieron una enorme competencia para los maestros de hacer coches.

También las fuentes legales prueban la trascendencia que la generalización de los coches tuvo en el ámbito urbanístico. Desde el siglo XVI se conocen normas que intentaron racionalizar el tráfico rodado y adaptar las ciudades a la nueva realidad circulatoria. Para ello se llevó a cabo el alineamiento, ensanchamiento y eliminación de obstáculos en las calles. El acondicionamiento de paseos de carruajes fue esencial a partir de ese momento y en el caso sevillano el principal escenario al respecto fue la Alameda de Hércules, que luego sirvió de modelo a numerosas alamedas americanas ${ }^{17}$.

Aunque apenas ha sido intuido aún por la historiografía, hay que mencionar que el uso del coche también afectó a la arquitectura. Muchos edificios tuvieron que ampliar sus portadas -empezando por el viejo Alcázar de los Austrias en Madrid-para que por ellas pasaran los vehículos, o ampliar sus apeaderos, para que pudieran maniobrar. De igual modo, se tuvieron que levantar cocheras para guardarlos. Así, en el Alcázar de Sevilla, con motivo de la presencia de la corte de Felipe V, su alcaide advirtió de la necesidad de ampliar las cocheras, ya que algunos

15 Teniendo en cuenta la importancia que Sevilla tuvo en el tráfico americano, cabe intuir que jugaría un papel significativo en él. No obstante, es poco lo que sabemos de la carrocería hispalense. De la segunda mitad del siglo XVI sólo conocemos los nombres de los primeros carpinteros que se especializaron en realizar coches y que se empezaron a denominar maestros de hacer coches. Y ya del XVIII, el surgimiento del correspondiente gremio. RECIO MIR, Álvaro: "Los maestros de hacer coches y su pugna con los pintores: un apunte sevillano de la dialéctica gremio-academia", Laboratorio de arte, 18, 2005, pp. 355369; y RECIO MIR, Álvaro: "La construcción de coches...", op. cit.

${ }^{16}$ LÓPEZ CASTÁN, Ángel: "La construcción de carruajes y el gremio de maestros de coches de la corte durante el siglo XVIII", Boletín del Museo e Instituto Camón Aznar, 23, 1986, pp. 96-115; y RECIO MIR, Álvaro: "La construcción de coches...”, op. cit.

${ }^{17}$ RECIO MIR, Álvaro: "Alamedas, paseos y carruajes: función y significación social en España y América (siglos XVI-XIX)”, Anuario de estudios americanos, 72, 2015, pp. 515-543. 
de los coches reales "no tienen donde encerrarse y principalmente para dos mui ricos que se han hecho en París para los serenísimos señores príncipe y princesa". Debido a ello hubo que levantar cuatro cocheras en $1732^{18}$.

En relación con el urbanismo y aun con la arquitectura en América destaca la Alameda de México, de la que el ya referido Gage dijo que "los galanes de esta ciudad se paseaban por allí diariamente sobre las cuatro de la tarde, algunos a caballo y la mayoría de ellos en carruajes con la mera intención de lucirse, por un campo sombreado al que llaman la Alameda [...] y allí se encuentran [...] unos dos mil carruajes" 19 . Con tanto tráfico no es de extrañar que se tuviera que regularizar. En este sentido, en 1785 se dictó una interesante normativa "para el curso o rúa que han de llevar los coches para formar sin confusión del paseo en los días de fiesta". Se establecían varias normas esenciales: la primera, que los coches, independientemente de la puerta por la que entraran, "tomarán el lado izquierdo arrimando la silla a los árboles lo que buenamente se pudiera o bien pasarán a la fila interior con el mismo cuidado de dexar los árboles a su izquierda". Indicaba también el punto donde "se tomará vuelta, para que todos los concurrentes se vean con comodidad y frecuencia". En tercer lugar, señalaba que "ningún coche debe pararse en la rúa, porque inmediatamente quedaría interrumpido el paseo, con incomodidad de todos". Por último, decía que "se espera que los dueños de los coches instruyan a sus respectivos cocheros" 20 .

La norma se acompañaba de un grabado de la planta de la Alameda, en la que se especifica gráficamente la referida circulación. A pesar de lo esquemático de los coches en ella representados, no deja de ser digno de mención el uso de tiros de dos y cuatro caballos. De igual modo, sorprende el elevado número de vehículos. Pero el tráfico llegó a ser tan enorme que no fue suficiente con regularlo de la manera que acabamos de referir. Ese mismo año, se abrieron dos puertas para peatones en las portadas de la Alameda, a los lados de las centrales que quedaron reservadas para coches y jinetes ${ }^{21}$.

Sin duda, la circulación de los coches es una cuestión esencial para comprender la evolución del urbanismo. El carácter regular de muchas ciudades americanas parecía propiciar el desarrollo del tráfico; no obstante, a ello hay que sumar una cuestión que se hizo recurrente: los empedrados. En tal sentido de las calles de México Diego Cisneros señaló que, por ser bien "trazadas y derechas parecen muy bien, aviendo llegado a su última perfección de estar empedradas y

${ }^{18}$ MARÍN FIDALGO, Ana: El Real Alcázar de Sevilla bajo los Borbones. El reinado de Felipe V (1700-1746). Sevilla, 2006, p. 186.

${ }_{19}$ GAGE, Thomas: Viajes por la Nueva España..., op. cit., p. 172.

${ }^{20}$ Gaceta de México, tomo I, 43, 26 de julio de 1785, p. 361.

${ }^{21}$ CASTRO, Efraín: "Alameda mexicana. Breve crónica de un viejo paseo", en Alameda, visión histórica y estética de la Alameda de la ciudad de México. México, 2001, pp. 57-58. 
aderezadas, en que no poco ha trabajado el vigilantísimo cuidado del excelentísimo señor marqués de Guadalcázar, porque antes las más o todas estaban desempedradas y siendo la naturaleza de la tierra salitral y pantanosa y las aguas del verano muchas y continuas en lo mejor de la ciudad se hundían los coches hasta los exes y los caballos hasta la cinchas de cuyos inconvenientes está agora segura"22.

Pero las fuentes legales también intentaron frenar el lujo de los coches. Tales normas son esenciales para conocer su materialidad, ya que resultan reflejo evidente de la realidad que intentaban controlar y que describían con detalle. Este asunto, a diferencia del anterior, ha sido hasta ahora apenas estudiado. Fueron numerosas tales normas durante el Antiguo Régimen, lo que incluso permitiría analizar la evolución formal, ornamental y tipológica de los coches. Aunque cabría retrotraerse a las Cortes de Valladolid de 1555, en esta ocasión traeremos a colación el caso de la pragmática sanción de 1723 de Felipe V. En esta norma, el punto décimo señalaba, en relación a las tapicerías de los carruajes: "mando que de aquí adelante en ningún coche, carroza, estufa, litera, calesa, ni furlón se pueda hazer ni haga bordado de oro, ni de seda, ni forrado de brocado, tela de oro, ni de plata, ni de seda alguna que lo tenga, ni con franjas ni trencillos ni otra guarnición alguna de puntas de oro, ni de plata y solamente se puedan hazer de terciopelos, damascos o de otras qualesquiera telas de sedas de las fabricadas en estos reinos y sus dominios... y solo se puedan guarnecer con franjas y galones de seda sin que se puedan hazer [...] con flecaduras que llaman de puntas de borlilla, campanilla, ni redecilla"23.

En cuanto al ornato de la caja de los coches la norma establecía que "tampoco se han de poder fabricar los dichos coches, carrozas estufas, literas, calesas ni furlones con labores ni sobrepuestos ni nada dorado, ni plateado ni pintado con ningún género de pinturas de dibuxo, entendiéndose por tales todo género de historiados, marinas boscajes, ornatos de flores, mascarones, lazos que llaman cogollos, escudos de armas, timbres de guerra, perspectivas y otra cualquier pintura que no sea de mármoles fingidos o jaspeados de un color todo eligiendo cada

${ }^{22}$ Citado en LÓPEZ ÁlVAREZ, Alejandro: "Los vehículos representativos...”, op. cit., p. 281. No faltaron las ocasiones en las que, debido a las grandes inundaciones que afectaron a la capital, los coches fueron sustituidos por canoas, de las que se dijo que eran "carrozas de menos costo, por lo mucho que tiene sustentar carrozas y animales que las tiren”. DE LA MAZA, Francisco: La ciudad de México en el siglo XVII. México, 1968, p. 29. Ello evidencia el paralelismo existente entre la carrocería y la carpintería de ribera -es decir, la construcción de barcos-, ya que tampoco en las embarcaciones dejó de haber elementos de innegable carácter artístico y grandes paralelismos con los coches.

${ }_{23}$ AMS (Archivo Municipal de Sevilla), sección V, escribanía de Cabildo, siglo XVIII, tomo 267, H-1326, doc. 29, f. 4-v. Sobre otras normas similares véase SEMPERE Y GUARINOS, Juan: Historia del luxo y de las leyes suntuarias de España. Madrid, 1788. 
uno el que quisiere. Y solo permito en los coches, carrozas, estufas, literas, furlones y calesas alguna moderada talla, no siendo excesiva y con calidad que la prohibición de coches aya de empezar desde que se publique esta ley y pragmática en quanto a que ninguno se pueda fabricar con dichos adornos debaxo de las penas en ella expresadas no desde el día de la publicación se puedan comprar no traer de fuera coches ni estufas contra el tenor de lo que queda dispuesto. A cuyo fin mando se haga luego registro por los alcaldes de mi casa y corte de los que actualmente ay en todas las casas sin excepción alguna" 24 .

El interés de esta larga cita es enorme ya que permite imaginar el grado de suntuosidad de los carruajes, con tallas doradas, pinturas de muy diversos géneros y el empleo de los tejidos más suntuosos. No obstante, lo más interesante es la obligación de que los coches existentes se registrasen. En el caso sevillano, el registro lo formaron 305 declaraciones en las que se incluyeron aproximadamente 580 coches. La información así acumulada resulta tan asombrosa como difícil de sistematizar. En primer lugar, permite saber quiénes eran los propietarios de coches que vivían entonces en Sevilla, desde títulos del Reino -como el marqués de Olivares, el del Casal o la condesa de Miraflores de los Ángeles- a militares, comerciantes, funcionarios, propietarios agrícolas, médicos o sacerdotes. Sin duda, se trata de un completo registro del patriciado local. De igual manera, conocemos cuántos coches tenía cada uno de ellos, en la mayoría de los casos uno, pero no falta quien contaba con más, como el conde de Torrejón que tenía cinco, igual que Juan Bautista Clarebout, mientras Alonso Tous de Monsalve, marqués de Valdeosera, tenía seis, los mismos que el marqués de Medina. Asimismo, señala nuestra fuente los modelos existentes: carrozas, berlinas, forlones, sillas volantes, estufas, calesas o cupés. Alude igualmente el registro a las tallas que adornaban los coches y a sus tapicerías, de las que se hacen minuciosas descripciones de sus almohadones, cortinas, flecos y distintos tejidos, como sedas chinas, terciopelos o damascos, no faltando telas bordadas. También se describen los herrajes de los coches, en ocasiones de bronce dorado, sus guarniciones y las labores de piel con las que contaban. A veces se incluyen sus usos, como la calesa de don Mateo $\mathrm{Mu}$ ñoz de Lara, que le servía "para ir a mi hazienda de campo que está a tres leguas desta ciudad al pago de Pero Mingo" o el pequeño furlón que declaraba don Juan Agustín de Torres, administrador de la Casa Cuna, utilizado por "los niños expósitos de dicha casa para salir a pedir limosna por las calles". Por último, también esta fuente hace a veces alusión a la procedencia de los vehículos, citándose ejemplos realizados en Sevilla, Barcelona, Madrid o, incluso, Inglaterra ${ }^{25}$.

${ }^{24}$ AMS, sección V, escribanía de Cabildo, siglo XVIII, tomo 267, H-1326, doc. 29, f. 5 -v.

${ }_{25}$ AMS, sección V, escribanía de Cabildo, siglo XVIII, tomo 267, H-1326, doc. 29, ff. $5 \mathrm{v}$-ss. 
Por traer a colación algún ejemplo, haremos referencia a la condesa de Miraflores de los Ángeles, que contaba con cuatro vehículos. Uno de ellos era "una estufa, el juego de color encarnado, pilares tallados y dorados, todos los yerros y sus mazorcas dorados, la caxa los tableros tallados y sobrepuestos dorados y vaquetas negras con tachuelas y bollones dorados y nueve remates encima del tejadillo echuras de floreros dorados y cinco chapas de bronce dorado, forrada la caja de terciopelo labrado de colores azul pajizo y morado y la franja del mismo color de borlillas con sus fundas y cubiertas del asiento del cochero del mesmo fondo y guarnición, con ocho bidrios corredizos, cinco cortinas de damasco de colores del dicho fondo" 26 .

Desde luego, la información que ofrece esta fuente es difícil de sistematizar. No obstante, nos gustaría al menos señalar la enorme variedad cromática de muchos de estos coches, los cuales estaban pintados de los más llamativos colores. El más frecuente fue el "color oja de oliva" o "de azituna", que suponemos antecedente del actual verde carruaje y que se ha convertido casi en distintivo cromático de los coches de caballos. No obstante, en otras ocasiones se dice que los tableros de las cajas de los carruajes eran de "color de ámbar", "café", "dorado liso", "pintada de sombras", "pintado de musgo", "color de plomo", "color de perla", "color fuego", "caoba oscuro", "coral", "verde esmeralda" o "color honesto" 27. Las referencias de Madrid son de pareja riqueza, ya que el inventario de las Caballerizas Reales de 1800 señala la existencia de coches pintados de color lacre, lila, turquí, café, limón o avellana, no faltando uno que era de "color piel de tigre" 28 .

A esos colores se unía un repertorio pictórico impresionante. Era general que los coches llevaran en sus puertas el escudo de su propietario, sus iniciales o cifras e infinidad de motivos decorativos, entre los que destacaban lazos, cintas, máscaras o flores. Pero quizá lo más interesante es que los coches fueron un soporte más de la pintura barroca, junto al lienzo y al muro, ya que abundaron los que contaron con completos repertorios iconográficos de asuntos tan variados como la mitología, la historia, el paisaje o la religión. Apenas nada se conserva de ello, salvo alguna excepción, como la silla de manos eucarística de la colección sevillana Morales-Marañón, con un completo ciclo pictórico ${ }^{29}$.

La repercusión de esta normativa sobre el lujo en otras ciudades de España y América resultaría fundamental para el conocimiento del coche en particular y de la historia del arte en general, ya que tanto los mejores pintores, como los

${ }^{26}$ AMS, sección V, escribanía de Cabildo, siglo XVIII, tomo 267, H-1326, doc. 29, declaración $\mathrm{n}^{\circ} 76$.

${ }^{27}$ RECIO MIR, Álvaro: "De color de hoja de oliva: la pintura de los coches en la Sevilla del siglo XVIII", Laboratorio de arte, 22, 2010, pp. 236-261.

28 TURMO, Isabel: Museo de carruajes. Madrid, 1969, p. 18.

${ }^{29}$ RECIO MIR, Álvaro: "Silla de manos eucarística", en PLEGUEZUELO, Alfonso y VALDIVIESO, Enrique (com.): Teatro de grandezas. Sevilla, 2007, pp. 360 y 361. 
más afamados escultores - partiendo del caso de Bernini en Italia-se dedicaron a ello. De nuevo en relación con Sevilla, tanto Domingo Martínez como Juan de Espinal, los dos más importantes pintores del siglo XVIII, decoraron $\operatorname{coches}^{30}$. Igualmente, en 1762 Cayetano de Acosta y Julián Jiménez, los más afamados retablistas sevillanos de la segunda mitad de dicho siglo, se quejaban de que los "maestros de coches ajustan por sí el tallado de los coches". Ello permite intuir que los mismos artífices que levantaban retablos se ocupaban del adorno de los coches, interesantísimo paralelismo artístico aún por estudiar ${ }^{31}$.

De México sabemos que en 1747 don Domingo Varcárcel tenía una "estufa muy capaz de garbosa y pulida talla, con todos sus hierros dorados y los rayos de las ruedas torneados, con ocho vidrios así grandes como hermosos, vestida por dentro de terciopelo carmesí con franjas de galón ancho, flecos, cordones y borlas de oro de Milán, y cuatro cortinas de damasco de color de oro con punta milanesa de oro". Por su parte, el conde de Regla contaba, entre otros coches, con una estufa de gala "forrada por dentro de terciopelo carmesí y guarnición de plata, colgadura blanca de seda y por fuera tallada y dorada" ${ }^{2}$. Además, en el caso mexicano se sumaban a los adornos habituales en Europa otros de un marcado carácter local, como chapados de carey y de concha ${ }^{33}$. Cabe por tanto intuir la existencia de vehículos que emplearan la afamada técnica del encochado. Incluso, en México cabría plantear paralelismos del coche con la arquitectura, ya que Manuel Tolsá, además de como arquitecto y escultor neoclásico, destacó como carrocero. De los coches salidos de su taller, la Gaceta de México decía que "los coches que en 1810 rodaban por las calles de la ciudad de México pasaban de los dos mil quinientos, y a medida que el lujo iba en aumento, crecía el buen gusto en ellos, pues a las pesadas tallas de los antiguos forlones y carrozas, había sucedido la sencillez en los adornos; a las antiguas molduras, los mejores charoles, comparables a los barnices extranjeros; porque es de advertir que ya por aquella fecha se fabricaban en México y en la casa de don Manuel Tolsá"34.

Ello evidencia el tránsito del modelo barroco de carácter francés al inglés, de signo neoclásico. Inglaterra arrebató a Francia a fines del siglo XVIII la supremacía mundial en la construcción de coches. De líneas y decoración mucho más sobrias que las francesas, los coches ingleses ganaron en seguridad, velocidad y confort, desarrollando a lo largo del siglo XIX una infinidad de modelos que se exportaron a todo el mundo. Caso pionero del uso de coches ingleses en la capital

${ }^{30}$ PLEGUEZUELO HERNÁNDEZ, Alfonso: Manuel Rivero. Los encargos artísticos de un mercader andaluz del siglo XVIII. Huelva, 2005, p. 143.

31 PLEGUEZUELO HERNÁNDEZ, Alfonso: "Sobre Cayetano de Acosta, escultor en piedra", Revista de arte sevillano, 2, 1982, pp. 35-42.

32 ROMERO DE TERREROS, Manuel: Las artes industriales..., op. cit., pp. 84-85.

${ }^{33}$ HERNÁNDEZ, Francisco Javier: Carruajes, sillas, jaeces..., op. cit., p. 3.

34 Ibidem. 
de Nueva España fue el que empleó el segundo conde de Revillagigedo en su entrada como virrey en 1789, que tenía esa procedencia y del que las fuentes señalan que "causó mucha novedad" 35 . A este respecto, podemos añadir un interesante ejemplo de 1815, cuando Juan Manuel de Gandasegui compró un landau en Londres de la prestigiosa casa carrocera británica Maberly para llevarlo a México ${ }^{36}$.

\section{FUENTES ICONOGRÁFICAS}

Las fuentes iconográficas son incontables, ya que es rara la pintura, grabado o dibujo que durante el Antiguo Régimen plasmase alguna vista de ciudad, tanto de Europa como de América, que no mostrase carruajes. La evolución de su número es prueba de su generalización, ya que si en las imágenes del siglo XVI aparecen con cierta timidez, conforme avanza su cronología se hacen más numerosos, hasta convertirse en ocasiones, al culminar el Antiguo Régimen, en protagonistas de estas vistas. No obstante, este tipo de fuentes presentan ciertas limitaciones, ya que no siempre fueron representados los coches con el detalle y la claridad que sería de desear para nuestros fines.

En relación al caso sevillano, la inmensa iconografía de la ciudad permite saber que su Alameda de Hércules se convirtió en un regularizado circuito de coches. De igual forma, las entradas reales, como la de Felipe V en 1729, fueron ocasión excelente para la exhibición de las más suntuosas carrozas de corte. También el empleo de carros triunfales en fiestas de todo tipo es asunto conocido, aunque apenas analizado (Figura 2) ${ }^{37}$.

En América las vistas de ciudades alcanzaron la categoría de particularizado género pictórico virreinal. Así, por lo que se refiere a Lima, no podemos dejar de citar la famosa vista de su plaza mayor de $1680^{38}$. En esta imagen nos encontramos con tres coches en los que podemos ver algunos elementos significativos. En primer lugar, todo parece indicar que sus ocupantes son féminas, ya que existió una enorme vinculación coche-mujer, de igual manera que se asociaba el varón al caballo, reminiscencia del ideal caballeresco medieval. Por otra parte, los coches se muestran aún algo primitivos, sin la influencia de las grandes carrozas francesas que por entonces se implantaban, ni de las berlinas que tanto éxito luego alcanzarían. No obstante, estos coches tenían las características básicas que evolucionarían y se desarrollarían. Así, sus cajas ya apuntan su clásica configuración

${ }^{35}$ RECIO MIR, Álvaro: "La carroza del virrey: el coche en Nueva España como atributo del poder", en MÍNGUEZ, Víctor (ed.): Las artes y la arquitectura del poder. Caste1lón, 2013, pp. 2425-2439.

${ }^{36}$ AGI (Archivo General de Indias de Sevilla), Estado, 98, $\mathrm{n}^{\circ} 38$.

${ }^{37}$ RECIO MIR, Álvaro: "Los maestros de hacer coches y su pugna con los pintores...", op. cit.

${ }^{38}$ SERRERA, Ramón Ma': Tráfico terrestre..., op. cit., pp. 305-308. 
trapezoidal, sus tejadillos abombados o su carácter cerrado. Por lo que se refiere a los tiros, los tres son de dos caballos, en disposición paralela que se conoce con el nombre de tronco. Los vehículos, siempre con las ruedas delanteras menores para ganar en maniobrabilidad, carecían de pescante, por lo que eran guiados por el cochero sobre uno de los caballos, lo que se conoce como postillón. Otro detalle relevante es el sistema de suspensión, en este caso mediante sopandas, correas de cuero que unían la caja a los trenes, de forma que al ir suspendida evitaba las irregularidades del suelo. Serían muchas las cuestiones que cabría destacar de esta fuente, como que el coche era un signo de distinción social de primer orden y que su utilidad no era solo ser transportado, ya que a ello sumaba su carácter de atalaya para ver la realidad circundante desde una cierta altura y, sobre todo, para que sus ocupantes fueran vistos en una suerte de trono rodante (Figura 3).

Del caso mexicano cabe empezar haciendo referencia a los coches que aparecen en sus biombos. En este sentido nos parece del máximo interés la hipótesis de Joaquín Bérchez, que apunta que el carácter móvil del biombo y la variedad de técnicas aplicables sobre él son cuestiones que también podemos encontrar en los coches, por lo que plantea una evolución paralela de ambas realidades artísticas ${ }^{39}$.

Muy interesante al respecto resulta el biombo de colección particular mexicana, que representa el coche de un virrey, al que sigue otro más modesto y una silla de manos. El carruaje virreinal está claramente individualizado, debido a que iba tirado por seis caballos. El número de estos fue una cuestión esencial en el marco del mundo cortesano. Los tiros de ocho estaban reservados a los reyes, los de seis a personas de sangre real o representantes del rey y los de cuatro a duques y arzobispos. El uso de tiros de seis caballos creó numerosas disputas entre los virreyes americanos y los prelados de Lima y México, ya que estos se arrogaron la prerrogativa del uso de los seis caballos, lo que los virreyes negaron con insistencia. En este caso concreto, son seis caballos dispuestos a la larga, en tres parejas. Ello obligaba al empleo de dos postillones, en una tipología que se suele denominar a la Daumont, a los que acompañaban otros lacayos de a pie. El primitivismo de este coche y del que le sigue resulta evidente ya que, por ejemplo, aún no están cerrados por vidrios. Por destacar algún elemento significativo, cabe decir que sus cajas estaban recubiertas de cordobán y claveteadas, algo muy frecuente en el siglo XVII. De igual tenor es el carruaje virreinal que aparece en el biombo del Museo de América de Madrid, cubierto de cordobán negro, del que destacaba su claveteado dorado. Esta tipología es la misma que encontramos en pinturas sevillanas de la misma época, como una de un auto de fe celebrado en 1660 (Figura 4) ${ }^{40}$.

${ }^{39}$ Así lo apunta en la ficha que le dedica al biombo de Juan Correa de las Artes liberales en BÉRCHEZ, Joaquín (com.): Los siglos de oro en los virreinatos de América 15501700. Madrid, 1999, p. 313.

${ }^{40}$ RECIO MIR, Álvaro: "La carroza del virrey...", op. cit. 
De 1695 es la vista de la plaza mayor de México de Cristóbal de Villalpando, en la que el número de coches es mucho mayor que en el caso Lima citado y que en los biombos anteriores. Además, parece apuntarse una cierta evolución de la carrocería, por lo que se refiere por ejemplo a los colores, mucho más variados en este caso. Incluso en esta ocasión se ha creído ver en el ángulo inferior izquierdo el carruaje del conde de Gálvez, virrey que encargó la pintura. Resulta llamativo el uniforme de los postillones y lacayos del coche, que ya sigue claramente modelos franceses. Algo parecido cabría referir de la vista de la misma plaza que se conserva en el Museo Nacional de Historia del castillo de Chapultepec ${ }^{41}$. La evolución del coche virreinal resulta aquí evidente. El modelo de las grandes carrozas francesas es claro, por ejemplo, en la existencia de pescante para el cochero, a pesar de que el coche se sigue guiando con postillones a la Daumont. La decoración y el colorido son ya realmente suntuosos y parecen haber olvidado la austeridad de la corte de los Austrias. En cuanto a su decoración, la imagen indica que se trata de pintura de motivos florales. En este caso el coche virreinal, tirado por seis caballos, va acompañado por una comitiva de coches más modestos y tirados por solo dos caballos, lo que vuelve a probar su carácter simbólico (Figura 5).

El futuro análisis de estas y de otras fuentes permitirá completar el rico panorama de la carrocería a ambos lados del Atlántico durante la Edad Moderna, entendida como una actividad histórica y artística de primer orden y de la que aquí solo hemos realizado un rápido apunte.

Fecha de recepción: 29 de octubre de 2017

Fecha de aceptación: 30 de enero de 2018

${ }^{41}$ SERRERA, Ramón Mª Tráfico terrestre..., op. cit., pp. 315-321. 


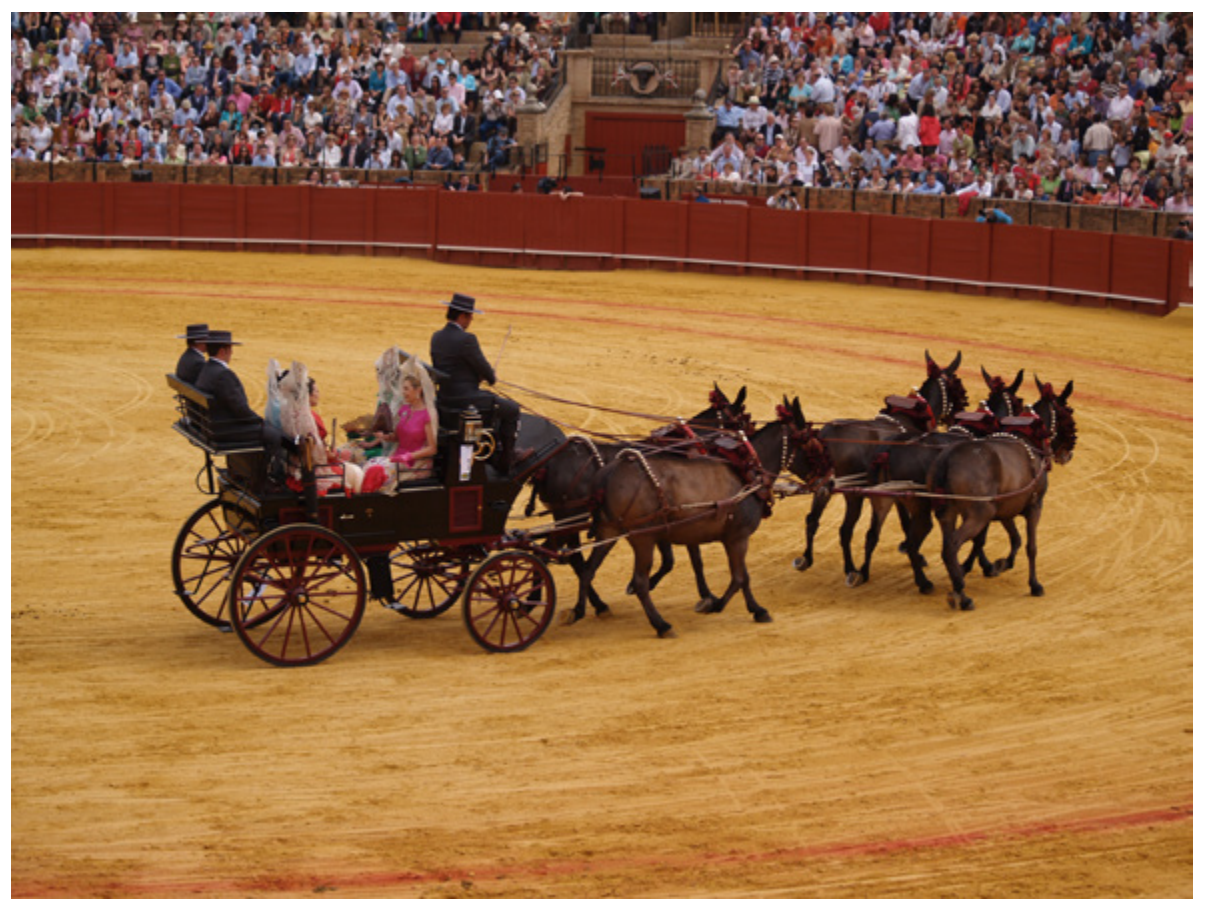

Figura 1. Exhibición de enganches de la Feria de Abril de Sevilla, 2008. 


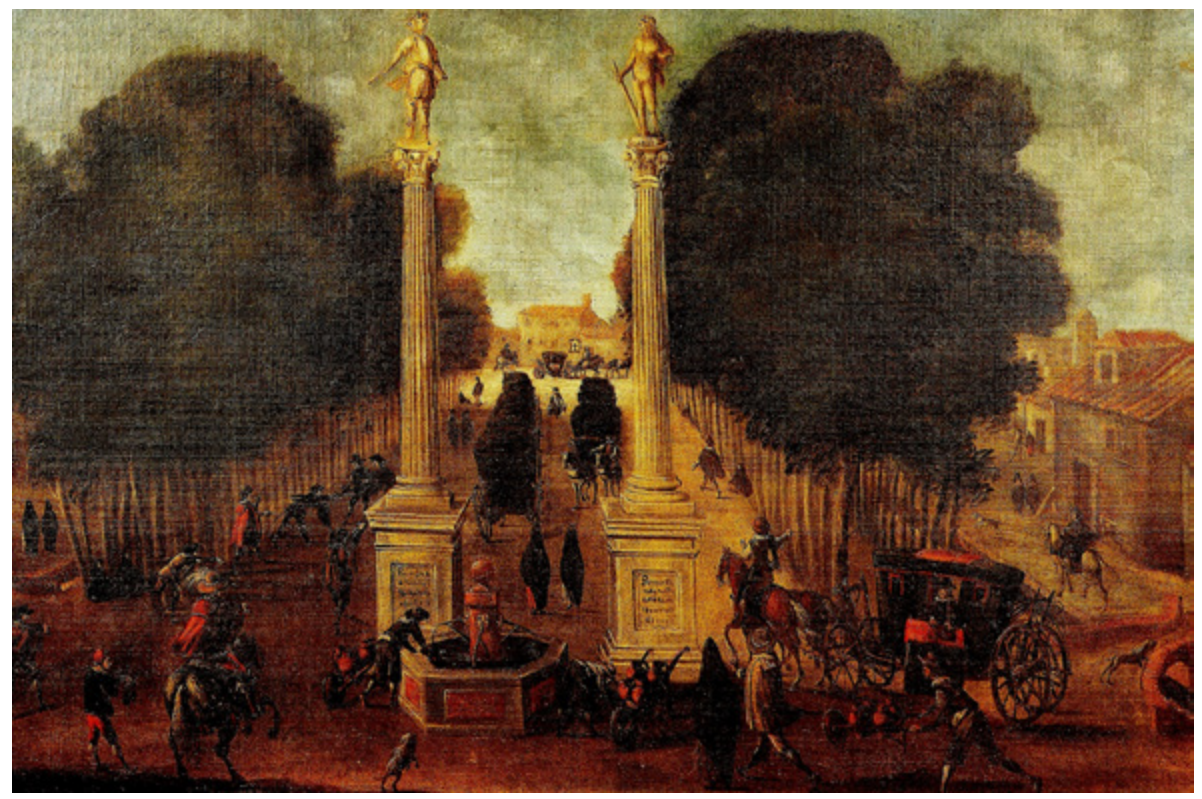

Figura 2. Anónimo, Alameda de Hércules de Sevilla, primera mitad del siglo XVII, Colegio de los Ingleses, Valladolid.

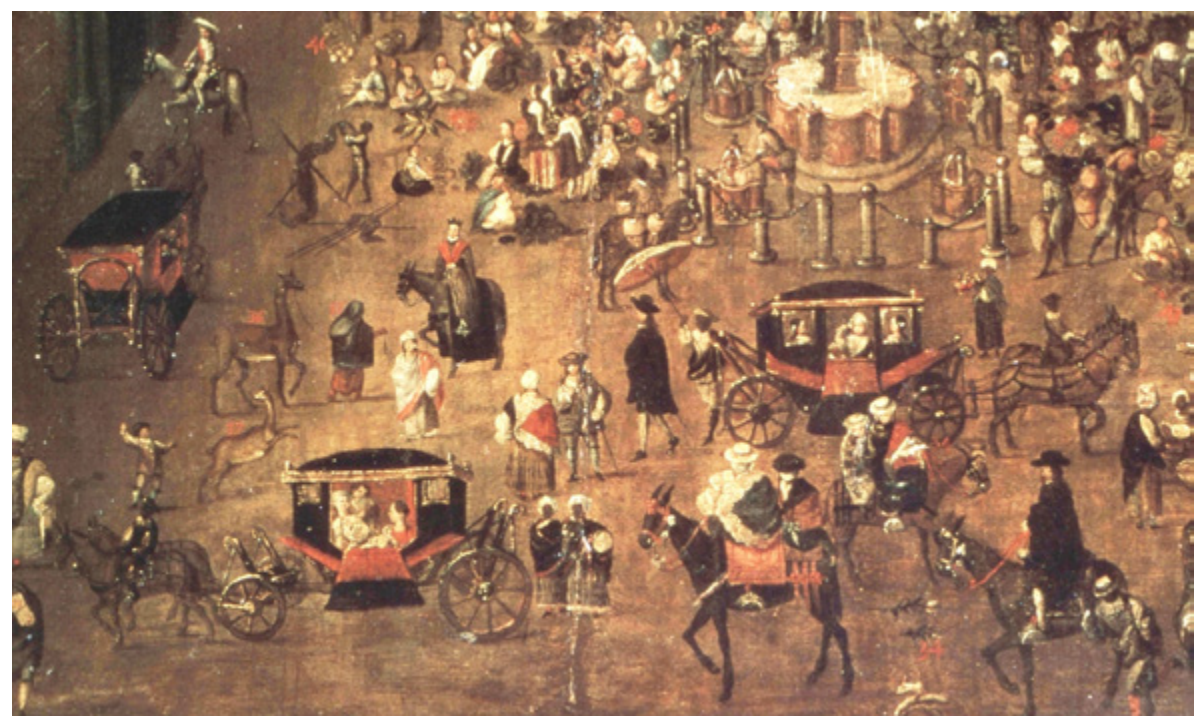

Figura 3. Anónimo, Plaza Mayor de Lima (detalle), 1680, Museo de América, Madrid. 


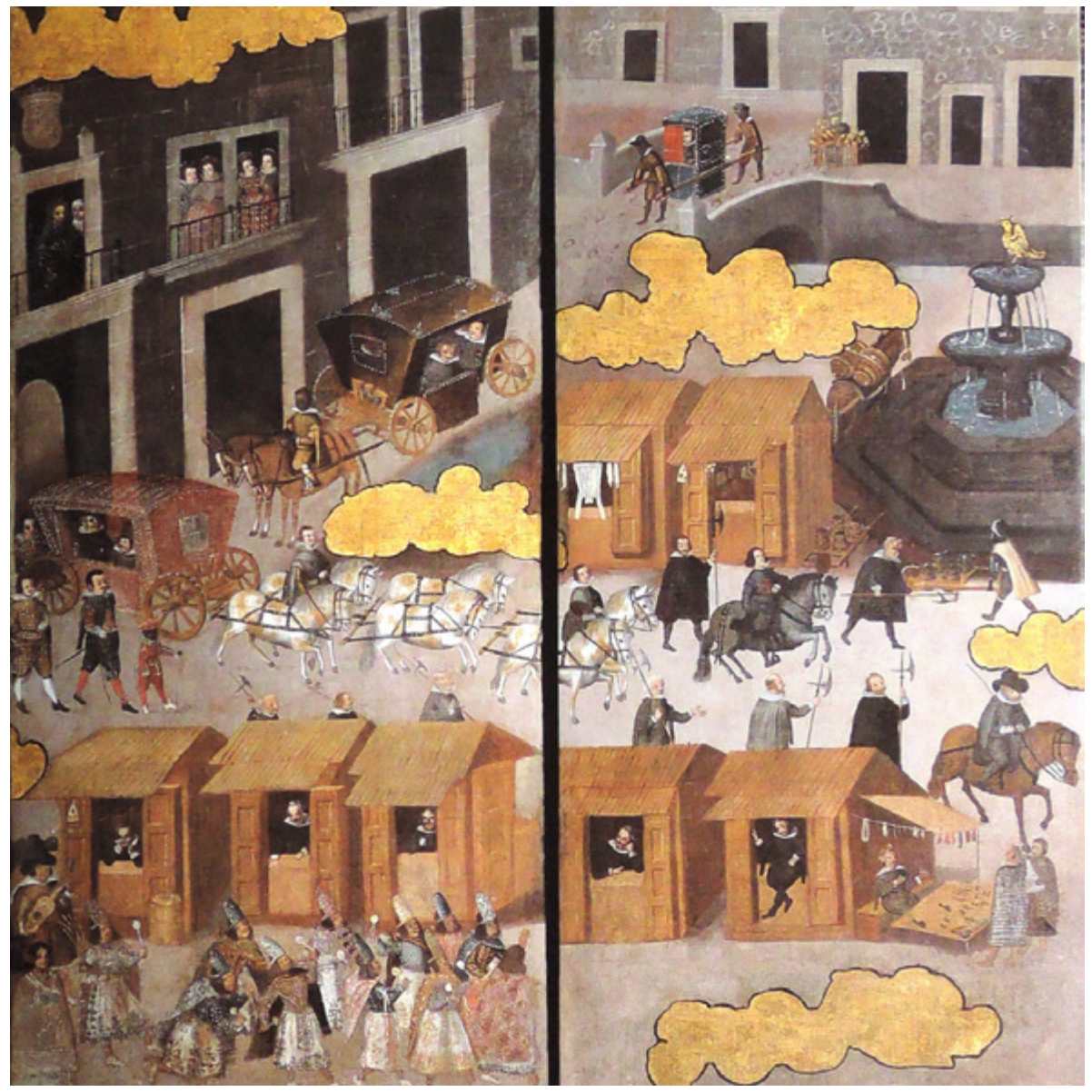

Figura 4. Anónimo, Vista del palacio del virrey de México (detalle), mediados del siglo XVII, colección particular. 


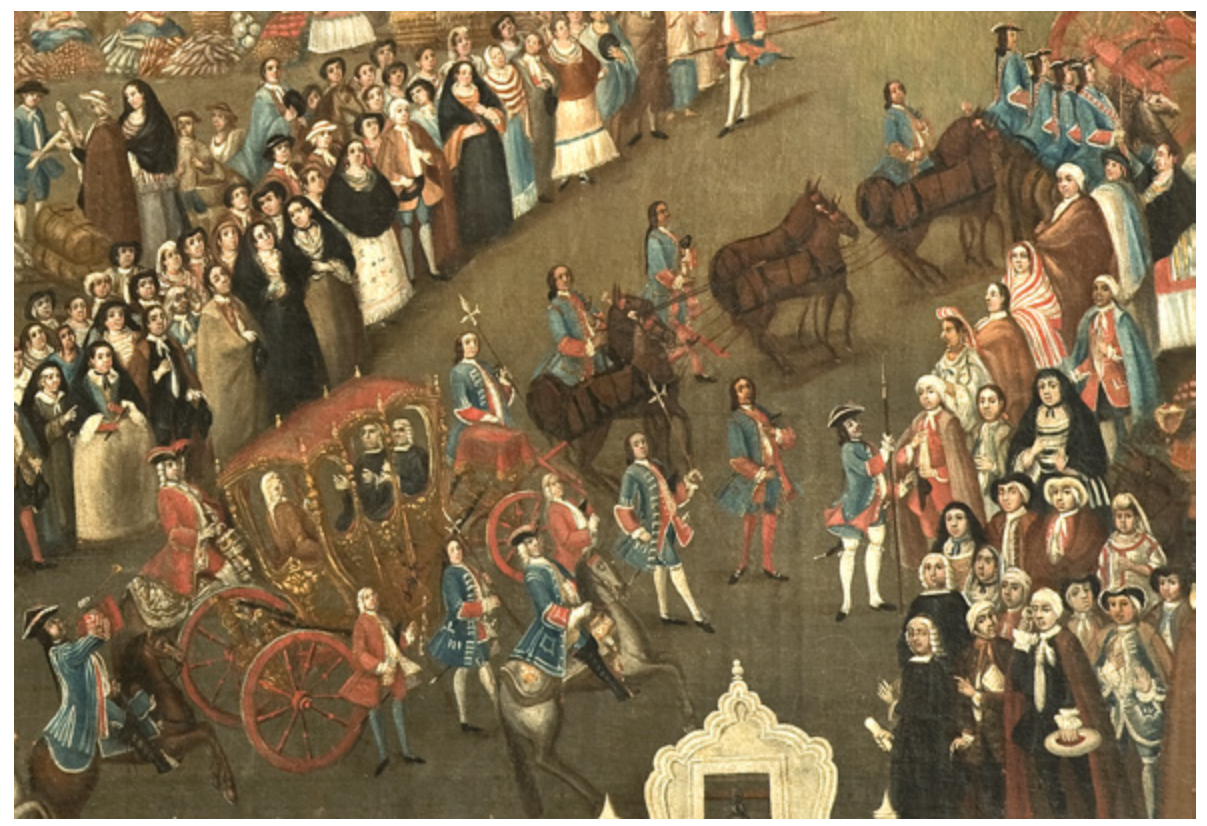

Figura 5. Anónimo mexicano, Plaza mayor de México (detalle), siglo XVIII, Museo Nacional de Historia, Castillo de Chapultepec, México. 